\title{
High-altitude retinopathy and retinal vascular dysregulation

\begin{abstract}
Purpose (a) To show that high-altitude retinopathy (HAR) is common at high altitudes even in well-acclimatised climbers and that it should not be regarded as part of the spectrum of benign mountain sickness but rather as a clinical sign with a separate aetiology. (b) To test the hypothesis that HAR could be interpreted as a clinical expression of 'ocular vascular dysregulation'.

Methods Both eyes of the 8 mountaineers of the First Vienna Himalayan Expedition in May/June 1996 were examined 2 weeks before departure to and 2 weeks after descent from a high altitude. Retinal blood flow was measured in the right eyes of 7 climbers, using the Heidelberg Retina Flowmeter (HRF). Results Two of the 8 climbers had bilateral retinal haemorrhage after the expedition. In 5 climbers chronic hypoxic exposure caused an increase in retinal blood flow between $+\mathbf{1 8 \%}$ and $+96 \%$, and in 2 climbers a decrease in retinal blood flow between $-21 \%$ and $-31 \%$. The 2 climbers (climbers 1 and 2) with bilateral retinal haemorrhage showed a significant increase in HRF parameters. Conclusions HAR may be a clinical sign of mountaineers with a tendency towards ocular vascular dysregulation. The pronounced increase in all haemodynamic parameters in the 2 climbers with retinal haemorrhage combined with a dilated epipapillary network 2 weeks after the exposure reflects a retinal vessel configuration, as might be expected at high altitudes under acute hypoxic stress. An inadequate autoregulatory response of the retinal circulation under conditions of chronic hypoxia may play an important part in the pathogenesis of HAR.
\end{abstract}

Key words Chronic hypoxia, Heidelberg Retina Flowmeter, High-altitude retinal haemorrhage, Retinal vascular dysregulation

High-altitude retinal haemorrhage (HARH) was first described by Singh et al. ${ }^{1}$ in 1969 as part of acute high-altitude sickness. Since then several authors ${ }^{1-17}$ have reported HARH in highaltitude mountaineers, but the data concerning the incidence of the disease are very varied.
Retinal haemorrhage at high altitude is usually devoid of symptoms, occurring between 4500 and $5500 \mathrm{~m}$, often as a result of extreme physical strain. ${ }^{2,5,7,8,10,11,13}$ It is not observed in subjects whose movements are restricted at altitude or who remain sedentary in simulated altitude chambers in spite of showing other altitude-related vascular changes. ${ }^{3,4}$ The haemorrhages are typically located in the nerve fibre layer, are flame- or wedge-shaped or 'dot and blot' haemorrhages, and in a peripapillary location. If visual symptoms occur, haemorrhages are often found in the macular area with a preretinal location. However, there appears to be no direct association between this phenomenon and high-altitude cerebral oedema or high-altitude pulmonary oedema. ${ }^{15,16}$ Young individuals and climbers who are well acclimatised are at higher risk of developing HARH.' ${ }^{75}$

The reduced atmospheric $\mathrm{O}_{2}$ partial pressure at extreme altitudes (about $60 \mathrm{mmHg}$ at $5000 \mathrm{~m}$ compared with $95 \mathrm{mmHg}$ at sea level) releases cascade-like mechanisms of adaptation as a response to high-altitude alkalosis (respiratory acclimatisation). ${ }^{18-20}$ Important features of highaltitude retinal changes are engorgement and tortuosity of the retinal vessels and optic disc hyperaemia, together with a reduced retinal circulation time, a concomitant increase in total blood flow and an absolute increase in retinal vascular blood volume. ${ }^{6,9-11,14,21,22}$

It is well known that retinal blood flow depends strongly on arterial $\mathrm{O}_{2}$. We therefore investigated the effect of chronic hypoxia at extreme altitudes on retinal blood flow after descent to sea level using the scanning laser Doppler flowmeter (Heidelberg Retina Flowmeter, HRF). ${ }^{21,23}$ This system combines laser Doppler flowmetry with laser scanning tomography, and permits two-dimensional mapping of the optical Doppler shift.

The purpose of this study was to show that high-altitude retinopathy (HAR) is common at high altitudes even in well-acclimatised climbers and to test the hypothesis that HAR could be interpreted as a clinical expression of 'ocular vascular dysregulation'. We investigated how the parameters 'velocity', 'flow' and 'volume' calculated in arbitrary units by the HRF instrument (HRF parameters) are 
modulated after long-term exposure to extreme altitudes (chronic hypoxia) and whether differences exist between climbers with and without HARH.

\section{Subjects and methods}

Eight mountaineers of the First Viennese Himalayan Expedition conducted in May/June 1996, whose destination was Cho Oyu (8201 m), were asked to come to an ophthalmological examination 2 weeks before and 2 weeks after exposure to high altitudes. The subjects (6 men and 2 women; ages between 38-55 years) were experienced climbers who had ventured several times to altitudes between 6000 and $8000 \mathrm{~m}$. The ascent to the Cho Oyu was preceded by a 12-day acclimatisation to altitudes up to $5000 \mathrm{~m}$ (Khumbu Himal). The actual climb started at Tingri (Tibet), where the base camp was set up $(5700 \mathrm{~m})$; subsequently camps were set up at altitudes between 6200 and $7500 \mathrm{~m}$. Three weeks were spent climbing between the base camp and an altitude of $7500 \mathrm{~m}$. Two climbers reached the peak; the others stopped at altitudes between 7500 and $7900 \mathrm{~m}$. During a rescue operation one injured person from another expedition had to be taken down to the base camp from an altitude of more than $7000 \mathrm{~m}$; this constituted an enormous mental and physical exertion.

Medication of general complaints relating to gastrointestinal symptoms, headaches, bronchitis and nocturnal dry coughs consisted of ofloxacin, metamizole and analgesic drugs (mixtures of acetylsalicylic acid, paracetamol and caffeine). Three climbers took the decision to take acetazolamide ( $250 \mathrm{mg} /$ day) for a period of 3 weeks to prevent high-altitude sickness.

Two weeks before and after exposure to the high altitude, both eyes of each mountaineer were examined. The investigation included a visual acuity test (Snellen), Amsler grid testing and slit-lamp examination. Fundus inspection was performed using a Volk lens (90 D) through tropicamide-induced pupil dilatation and a fundus photograph was taken of each eye (Canon fundus camera).

Retinal blood flow was measured in the right eyes of 7 climbers with the Heidelberg Retina Flowmeter (HRF; Heidelberg Engineering, Heidelberg, Germany). The principles of laser Doppler flowmetry have been described in detail by Bonner and Nossal. ${ }^{24}$ Briefly, the vascularised tissue is illuminated by coherent laser light. Scattering on moving red blood cells (RBCs) leads to a frequency shift in the scattered light. In contrast, static scatterers in tissue do not change light frequency but lead to randomisation of light directions impinging on RBCs. This light diffusing in vascularised tissue leads to a widening of the spectrum of scattered light (Doppler shift power spectrum, DSPS). From this DSPS the mean RBC velocity (vel), blood volume (vol), and blood flow (flw) can be calculated. ${ }^{24}$ These parameters are calculated from the backscattered light for each point during the scanning process. The procedure of data sampling and the confocal optical system are described in detail by Michelson et al. ${ }^{21,23,25}$ The line sample frequency is

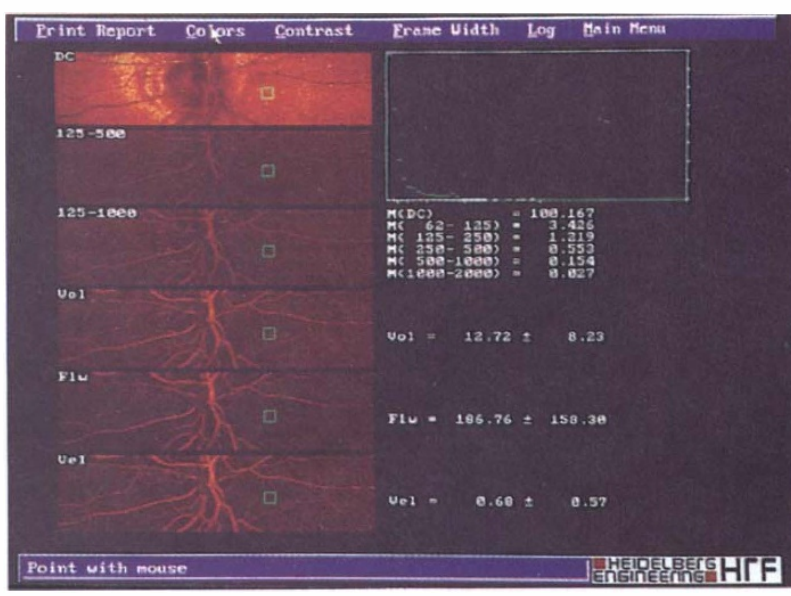

Fig. 1. Ophthalmoscopic (DC) and perfusion images (vol, flw, vel). The square marked in green, inferonasal, reflects a $10 \times 10$ pixel area for calculation of retinal haemodynamic parameters in arbitrary units.

$4000 \mathrm{~Hz}$ and frequencies $<125 \mathrm{~Hz}$ are excluded for Fast Fourier Transform. From the calculated RBC velocity, blood volume, and blood flow, a two-dimensional map of retinal perfusion is created. Hence these parameters can be quantified in relative units for any image point. In the present study four $10 \times 10$ pixel areas were selected for calculation of retinal haemodynamic parameters (Fig. 1). The areas were in peripapillary supero- and inferotemporal and supero- and inferonasal locations. The measurements were performed in regions without major surface vessels and without haemorrhage. From the data obtained, mean values of the different haemodynamic parameters were calculated. For data description HRF parameters were expressed as percentage change from baseline.

An exact Wilcoxon two-sample test was used to evaluate the differences in volume, flow and velocity between the climbers who developed HARH and those who did not. A $p$ value less than 0.1 was considered to show a statistical trend. All calculations were performed using SAS 6.12 for Windows.

\section{Results}

None of the 8 climbers had any signs of ocular pathology before departure. Two of the 8 had bilateral retinal haemorrhage after the expedition. The haemorrhages were all located in the nerve fibre layer, were flame- and wedge-shaped and were within 2 disc diameters of the optic disc. An additional haemorrhage in a preretinal location was found close to the macular region in climber 1 (Fig. 2). Climber 2, a 48-year-old woman, had a medical history of migraine and frequent headaches both in the past few years and during her stay in the base camp (Fig. 3). Disc hyperaemia was found in both eyes of climbers 1 and 2, a change not observed in the other mountaineers included in the study. The 2 climbers who had reached the peak were free of retinal changes. All haemorrhages had resolved at the post-expedition checkup performed 3 months later. 


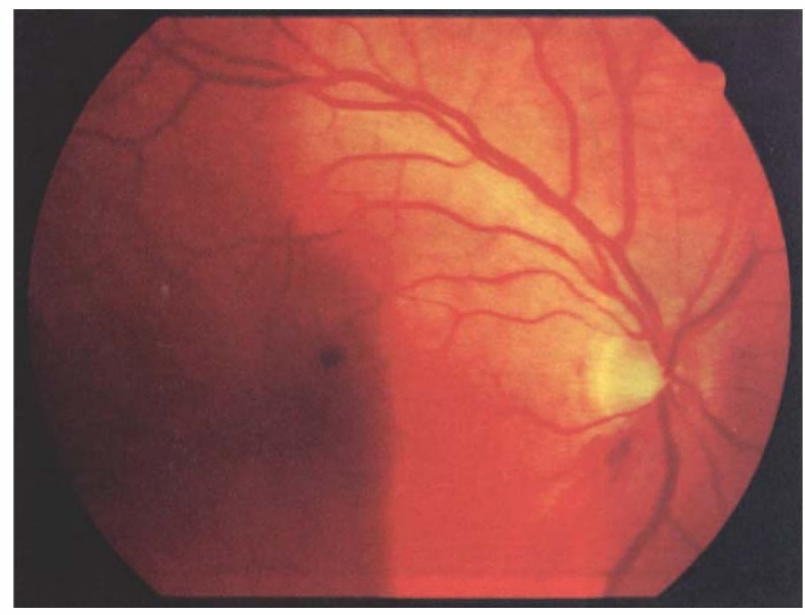

Fig. 2. Climber 1. Fundus photograph of the right eye showing peripapillary flame-shaped haemorrhages, disc hyperaemia and an additional haemorrhage in a preretinal location close to the macular region.

The changes in HRF parameters following chronic hypoxic exposure are shown in Fig. 4. The mean values before and after the expedition of the four $10 \times 10$ pixel areas just nasal and temporal to the disc are summarised in Table 1. The values of HRF parameters increased in 5 eyes. In these eyes chronic hypoxic exposure caused an increase in volume between $+3 \%$ and $+81 \%$, in flow between $+18 \%$ and $+96 \%$ and in velocity of $+5 \%$ and $+90 \%$ in the areas under study. The HRF parameters had reduced in 2 eyes. Chronic hypoxic exposure caused a reduction in volume between $-19 \%$ and $-34 \%$, in flow between $-21 \%$ and $-31 \%$ and in velocity between $-20 \%$ and $-30 \%$. The 2 climbers (climbers 1 and 2) with retinal haemorrhage had a distinct increase in HRF parameters (Fig. 4). However, because of the small number of eyes the difference was not statistically significant, but show a statistical trend $(p=0.0952)$.

The relationship between the changes in HRF parameters and the maximum altitude reached by each climber, the use of acetazolamide and the development of HARH are shown in Table 2. Headache, nausea, cough

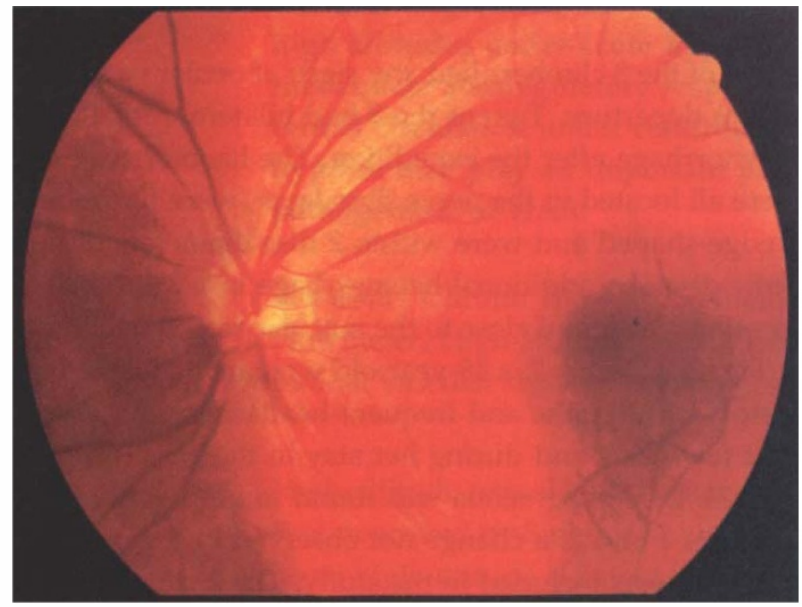

Fig. 3. Climber 2. Fundus photograph of the left eye showing peripapillary flame-shaped haemorrhages located in the nerve fibre layer and disc hyperaemia. and shortness of breath were the most common symptoms amongst the 8 climbers. None had severe symptoms of acute mountain sickness.

\section{Discussion}

Several recent reports ${ }^{1-17}$ have discussed the pathogenesis of high-altitude retinal haemorrhages (HARH), suggesting causative roles for increased retinal blood flow, dilatation of vessels in response to hypoxia, increased venous pressure tranmitted by coughing or straining ${ }^{26,27}$ and changes in intraocular pressure during physical exertion. Some authors emphasise the high incidence of concomitant headache. ${ }^{8}$

In the present study bilateral retinal haemorrhage occurred in 2 of 8 climbers (25\%). Incidences of about $28-36 \%$ have been quoted for climbers ascending to 5400-8167 m. 2,7,8,15 To compare individuals with and without HARH, medical history, physical examinations, the use of acetazolamide and the individual highest altitude attained were studied for potentially relevant factors (Table 1). In our study, there was no evidence of a relationship between the development of retinal haemorrhage and one of these factors, with the exception of a possible relationship between HARH and vascular headache. The female mountaineer (climber 2) with bilateral haemorrhage had had migraines in her youth and frequent headaches, both in the past few years and during her stay at the base camp. Schuhmacher et al. ${ }^{8}$ investigated the relationship between vasospastic headache and the incidence of HARH. He found that mountaineers with a medical history of migraine suffer more frequently from high-altitude headaches, and that the incidence of retinal haemorrhage appears to be closely related to the occurrence and intensity of altitude headache. Climber 1, who also had bilateral haemorrhage, was the head of the expedition. Thus, in addition to the physical strain he was subjected to enormous psychological stress.

Why did 2 climbers in a well-acclimatised group under similar conditions develop retinal haemorrhages? Both vasospastic headaches and increased psychological strain could be potential risk factors that contribute to an inadequate autoregulatory response of retinal circulation under conditions of chronic hypoxia. An imbalance of endothelium-derived relaxing and contracting factors $^{28,29}$ could be important for the development of HARH. Endothelium dysfunction is also thought to contribute to vasospastic events in some forms of low tension glaucoma associated with vasospastic headache and the Raynaud phenomenon. ${ }^{29}$

Regarding the question of whether there is an association between the occurrence of HARH and an inadequate retinal autoregulation under conditions of chronic hypoxia, we investigated the effect of chronic hypoxia on HRF parameters 2 weeks after the exposure (Table 1). The HRF permits assessment of retinal blood flow at the capillary level, ${ }^{21,23-25}$ the source of these haemorrhages. Recently some studies have investigated how retinal haemodynamic parameters are modulated 

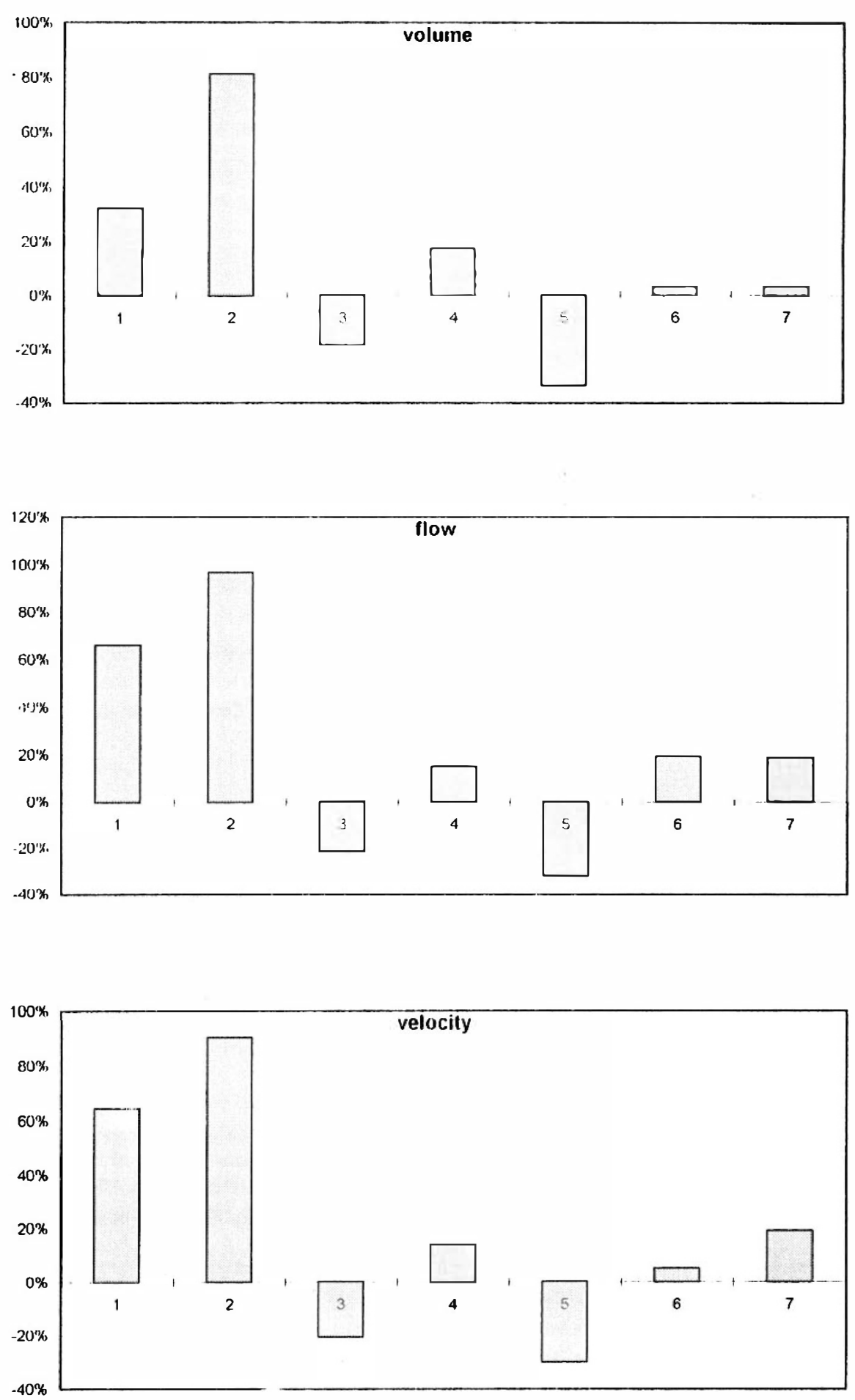

Fig. 4. Changes in HRF parameters of all seven climbers following chronic hypoxic exposure. The HRF parameters volume, flow and velocity were expressed as the percentage change compared with baseline values.

after short-term exposure (10 $\mathrm{min})$ to stimuli which increase or reduce blood flow. ${ }^{22,30-32}$ These results showed that scanning laser Doppler flowmetry has an acceptable reproducibility and is appropriate to depict the effect of graded changes in $\mathrm{pO}_{2}$ on retinal haemodynamics.

Our investigations showed a marked increase in all haemodynamic parameters in the two climbers with bilateral haemorrhage 2 weeks after exposure (Fig. 5). Statistical analysis tested the hypotheses that there is a relationship between this increase in volume, flow and
Table 1. Mean values of the four $10 \times 10$ pixel areas in arbitrary units before (pre) and after (post) the expedition

\begin{tabular}{|c|c|c|c|c|c|c|}
\hline \multirow{2}{*}{$\begin{array}{l}\text { Climber } \\
\text { no. }^{a}\end{array}$} & \multicolumn{2}{|c|}{ Volume } & \multicolumn{2}{|c|}{ Flow } & \multicolumn{2}{|c|}{ Velocity } \\
\hline & Pre & Post & Pre & Post & Pre & Post \\
\hline 1 & 11.00 & 14.56 & 162.41 & 269.27 & 0.60 & 0.98 \\
\hline 2 & 9.12 & 16.39 & 165.37 & 324.70 & 0.61 & 1.16 \\
\hline 3 & 14.36 & 11.69 & 278.16 & 218.90 & 1.01 & 0.81 \\
\hline 4 & 10.25 & 12.04 & 197.08 & 226.01 & 0.73 & 0.83 \\
\hline 5 & 16.96 & 11.26 & 276.58 & 188.26 & 0.99 & 0.69 \\
\hline 6 & 11.67 & 12.03 & 210.71 & 250.59 & 0.78 & 0.82 \\
\hline 7 & 13.16 & 13.57 & 196.67 & 232.75 & 0.72 & 0.86 \\
\hline
\end{tabular}

${ }^{a}$ Data are from the right eye. 
Table 2. Relationship between the HRF parameter changes and the use of acetazolamide, the maximum altitude reached by each climber and the development of high-altitude retinal haemorrhage (HARH)

\begin{tabular}{|c|c|c|c|c|c|c|c|c|}
\hline \multirow[b]{2}{*}{ Climber no. $^{a}$} & \multirow[b]{2}{*}{ Age (years) } & \multirow[b]{2}{*}{ Sex } & \multicolumn{3}{|c|}{ HRF parameters } & \multirow[b]{2}{*}{ Max. altitude (m) } & \multirow[b]{2}{*}{ Acetazolamide } & \multirow[b]{2}{*}{ HARH } \\
\hline & & & vol & flw & vel & & & \\
\hline 1 & 54 & $\mathrm{M}$ & $+32 \%$ & $+66 \%$ & $+64 \%$ & 7500 & Yes & Yes \\
\hline 2 & 48 & $\mathrm{~F}$ & $+81 \%$ & $+96 \%$ & $+90 \%$ & 7500 & Yes & Yes \\
\hline 3 & 55 & $\mathrm{M}$ & $-19 \%$ & $-21 \%$ & $-20 \%$ & 7900 & No & No \\
\hline 4 & 55 & $\mathrm{M}$ & $+17 \%$ & $+15 \%$ & $+14 \%$ & 7900 & No & No \\
\hline 5 & 55 & $\mathrm{M}$ & $-34 \%$ & $-32 \%$ & $-30 \%$ & 7500 & No & No \\
\hline 6 & 55 & $\mathrm{M}$ & $+3 \%$ & $+19 \%$ & $+5 \%$ & 8201 & Yes & No \\
\hline 7 & 38 & $\mathrm{~F}$ & $+3 \%$ & $+18 \%$ & $+19 \%$ & 8201 & Yes & No \\
\hline
\end{tabular}

${ }^{\mathrm{a}}$ Data are from the right eye.

velocity and the occurrence of HARH. Although the number of eyes tested was too small to show a statistically significant diifference, the collected data showed a statistical trend. Combined with the dilated epipapillary network the results reflect a retinal vessel configuration as might be expected at high altitude under acute hypoxic stress. During a prolonged stay at high altitude up to about $5300 \mathrm{~m}$, systemic compensatory mechanisms start to occur as a result of hypoxia. After the phase of acclimatisation, better oxygenation should lead to a return to the basic proper tonus in the retinal vessels. The release of vasoconstricting factors by the endothelium (endothelin 1, thromboxane $\mathrm{A}_{2}$ prostaglandin $\mathrm{H}_{2}$, angiotensin-converting enzyme $)^{28,29}$ and the reduced blood flow may effectively check pressure fluctuations, thus re-establishing tonicity. The decrease in all HRF parameters in climbers 3 and 5 after the exposure to high altitudes (Table 1) could be interpreted in this way as a sign of very good retinal acclimatisation.

This retinal process of acclimatisation was documented on site by Frayser et al. ${ }^{3}$ The effect of exposure to an altitude of $5300 \mathrm{~m}$ upon retinal circulation has been studied in acclimatised individuals and in those exposed for a short period. In those subjects who had spent enough time at high altitude to become fully acclimatised, the degree of vasodilation and flow changes was significantly less than it was in acutely exposed individuals. The well-acclimatised individuals had significantly less hypoxia. Brinchmann-Hansen and Kjell Myhre ${ }^{12}$ described changes in the retinal vessels 2 weeks after exposure to high altitudes. Using a 'scanning microdensitometer', groups of vessels arranged according to size were compared, revealing a tendency of the smaller arterioles and venules to dilate whereas the larger ones were constricted. Unfortunately, the evaluation did not make a distinction between subjects with and without retinal haemorrhage.

In the event of HARH it would not be a case of predominant vasoconstriction but, rather, its delayed onset in response to hypoxia-induced vasodilatation, of which the most important mediators are the prostaglandins, endothelium-derived hyperpolarising factor and hydrogen peroxide. ${ }^{28}$ Maximum vasodilatation, which is useful initially for nutritive reasons, would be deleterious in the phase of acclimatisation; the delicate network of retinal capillaries cannot withstand this oversupply and additional fluctuations in blood pressure under physical strain may, in turn, cause damage to capillary walls and subsequently lead to retinal haemorrhage.

In conclusion, our results support the theory that HARH should not be regarded as part of the spectrum of benign mountain sickness but rather as a clinical sign with a separate aetiology, which is likely to be multifactorial. Different factors as mentioned above may influence 'individual susceptibility'. Although the results of this study are limited, our data suggest that mountaineers with a tendency towards ocular vascular dysregulation are at higher risk of developing retinal haemorrhage. The medical-psychological project Pyramide 2001, planned to start in autumn 2001 at an altitude of $5300 \mathrm{~m}$, should provide ample opportunity to carry out further investigations. In line with the growing expertise about retinal autoregulation on the basis of endothelial dysfunction, it may also be possible to define a risk group for HARH. Because of the increasing popularity of high-altitude pursuits it is necessary to develop a concept of prevention and treatment.

We are very grateful to Prof. Dr H. Frisch, the medical doctor on this mountaineering expedition, for his exact medical reports and for his helpful comments on this manuscript. We also thank the members of the First Vienna Himalayan Expedition who, through their willingness to undergo the ophthalmological examinations, have contributed to the understanding of the conditions discussed.

\section{References}

1. Singh I, Khanna PK, Shrivastava MC, Lal M, Roy SB, Subramanyam SV. Acute mountain sickness. N Engl J Med 1969;280:175-84.

2. Frayser R, Houston C, Bryan AC, Rennie ID. Retinal hemorrhage at high altitude. N Engl J Med 1970;282:1183-4.

3. Frayser R, Houston C, Gray GW, Bryan AC, Rennie ID. The response of the retinal circulation to altitude. Arch Intern Med 1971;127:708-11.

4. Kobrick JL, Appleton B. Effects of extended hypoxia on visual performance and retinal vascular state. J Appl Physiol 1971;31:357-62.

5. Shults WT, Swan KC. High altitude retinopathy in mountain climbers. Arch Ophthalmol 1975;93:401-3.

6. Wiedmann M. High altitude retinal hemorrhage. Arch Ophthalmol 1975;93:395-400.

7. Rennie D, Morrissey J. Retinal changes in Himalayan climbers. Arch Ophthalmol 1975;93:395-400. 
8. Schuhmacher GA, Petajan JH. High altitude stress and retinal hemorrhage. Arch Environ Health 1975;30:217-21.

9. Clarke C, Duff J. Mountain sickness, retinal hemorrhages and acclimatisation on Mount Everest in 1975. BMJ 1976;II:496-7.

10. Hackett PH, Rennie D. Rales, peripheral edema, retinal hemorrhage and acute mountain sickness. Am J Med 1979;67:214-8.

11. Clarke C. High altitude cerebral edema. Int J Sports Med 1988;9:170-4

12. Brinchmann-Hansen O, Myhre K. Blood pressure, intraocular pressure and retinal vessels after high altitude mountain exposure. Aviat Space Med Environ 1989;60:970-6.

13. Butler FK, Harris DJ, Reynolds RD. Altitude retinopathy on Mount Everest 1989. Ophthalmology 1992;99:739-46.

14. Sutton JR. Mountain sickness. Neurol Clin 1992;4:1015-30.

15. McLaren R. Retinal haemorrhage in Himalayan Mountaineers. JR Army Med Corps 1995;141:25-28.2

16. McLaren R. Asymptomatic retinal haemorrhage is common at altitude. BMJ 1995;311:812-3.

17. Lang G, Kuba G. High altitude retinopathy. Am J Ophthalmol 1997;123:418-20.

18. Berghold F, Schobersberger W. Ätiologie, Klinik und Therapie der Höhenkrankheit. WMW 1994;7:125-9.

19. Berghold F, Schaffert W, Pallasmann K. Voraussetzungen und Richtlinien für die Akklimatisation an grosse und extreme Höhen zur Vorbeugung der Höhenkrankheit. WMW 1991;11:243-8.

20. Bärtsch P. Wer wird bergkrank? Schweiz Med Wochenschr 1992;122:307-14.

21. Michelson G, Groh M, Langhans M, Schmauss B. Zweidimensionale Kartierung der retinalen und papillären Mikrozirkulation mittels Scanning-Laser-DopplerFlowmetrie. Klin Monatsbl Augenheilkd 1995;207:180-90.
22. Strenn K, Menapace R, Rainer G, Findl O, Woltz M, Schmetterer L. Reproducibility and sensitivity of scanning laser Doppler-flowmetry during graded changes in $\mathrm{pO}_{2}$. $\mathrm{Br} \mathrm{J}$ Ophthalmol 1997;81:360-4.

23. Michelson G, Schmauss B, Langhans MJ, Harazny J, Groh MJM. Principle, validity, and reliability of scanning laser Doppler flowmetry. J Glaucoma 1996;5:99-105.

24. Bonner R, Nossal R. Principles of laser-Doppler flowmetry in laser-Doppler blood flowmetry. In: Shepard AP, Öberg AP, editors. Developments in cardiovascular medicine 107. Boston: Kluwer Academic, 1990:17-45.

25. Michelson G, Langhans MJ, Groh M. Clinical investigation of the combination of a scanning laser ophthalmoscope and laser Doppler flowmeter. Ger J Ophthalmol 1995;4:342-9.

26. Schipper L. Valsalvamanöver: nicht immer gutartig. Klin Monatsbl Augenheilkd 1991;198:457-9.

27. Duane TH. Valsalva hemorrhagic retinopathy. Am J Ophthalmol 1973;??:637-42.

28. Haeflinger I, Meyer P, Flammer J, Lüscher T. The vascular endothelium as a regulator of the ocular circulation: A new concept in ophthalmology? Surv Ophthalmol 1994;39:123-32.

29. Kaiser HJ, Flammer J, Hendrickson PH. Ocular blood flow: new insights into the pathogenesis of ocular diseases. Glaucoma meeting. Basel: Karger-Verlag, 1995.

30. Riva CE, Harino S, Petrig BL, Shonat RD. Laser Doppler flowmetry in the optic nerve. Exp Eye Res 1992;55:499-506.

31. Lundmark P, Rawij M, Flanagan J, Trope G. Variability of blood flow measurements using the Heidelberger Doppler Flowmeter. Invest Ophthalmol Vis Sci 1996;37(Suppl):265.

32. Lietz A, Hendrickson PH, Flammer J, Haeflieger IO. Ocular blood flow modulation and HRF parameters at the papilla. Invest Ophthalmol Vis Sci 1996;37:462. 